\title{
Evaluating Safety Practices Associated With Use of Household Pesticides: An Interventional Study in Kurmin Mashi Rural Community, Kaduna, Nigeria
}

\author{
${ }^{* 1}$ ADJE, UD; ${ }^{2}$ AREMU, TO \\ ${ }^{1}$ Dept. of Clinical Pharmacy, Delta State University, Abraka, Nigeria \\ ${ }^{2}$ Kaduna State Drugs and Medical Supplies Management Agency. Kaduna, Nigeria \\ *Corresponding Author_Email: a_udave77@yahoo.com;Tel: 08023241125
}

\begin{abstract}
Many households in developing countries routinely use pesticides without any safety considerations. The objective of this study was to determine types of pesticides and pesticide-use practices of the residents, to determine self-reported adverse effects resulting from pesticide use and to assess the impact of educational intervention on pesticide use behavior in the study area. Commercially available pesticide samples were collected from pesticide vendors in the area. Pre -tested questionnaires were distributed to 375 family heads. Data was expressed as frequency and percentages. Educational intervention on safe pesticide use was carried out. Pre and post intervention behavior were compared using paired t test. Relationship between demographic variables and pesticide use practices were explored using Chi Square statistics. A p value of less than 0.05 was considered significant. Prevalent pests were mosquitoes, cockroaches, rats, bedbugs, ants, termites, houseflies, ticks and scorpion. The major constituent of pesticides in this environment was Dichlorvos (DDVP). Many commercially available pesticides were unlabeled. Nearly half, $48.8 \%$ had used pesticides in the home. More than three quarters, $78.7 \%$ indicated that they read instructions before using pesticides. More than one third, $36 \%$ had experienced health problems attributed to pesticide use. Many locally available pesticides were unlabeled. Majority of labelled pesticides contained mainly Diclorvos (DDPV). Unsafe pesticide handling practices were common. The most common self -reported adverse effect was respiratory symptoms. Educational intervention increased in the proportion of respondents that used of non-chemical methods and adopted safer pesticide use practices.
\end{abstract}

\section{DOI: https://dx.doi.org/10.4314/jasem.v24i2.14}

Copyright: Copyright $\left({ }_{0} 2020\right.$ Adje and Aremu. This is an open access article distributed under the Creative Commons Attribution License (CCL), which permits unrestricted use, distribution, and reproduction in any medium, provided the original work is properly cited.

Dates: Received: 16 November 2019; Revised: 11 January 2020; Accepted: 22 February 2020

Keywords: Pesticides, Diclorvos (DDPV), Educational Intervention, Pharmacist, Nigeria

Diseases transmitted by vectors are a major health concern globally and cause millions of deaths annually (Guinovart et al, 2006). The burden is highest in sub Saharan Africa due in part to the tropical climate, poor environmental conditions and lifestyles that result in greater contact with vectors (Wilcox et al, 2019). Also, Infrastructural Inadequacies and limited financial resources hamper necessary effective national vector control and pesticide distribution programs (Gubler, 1998). Household pesticide use is therefore quite common in developing countries. Use of pesticides by individuals at the household level poses serious threat to health. The World Health Organization estimates that annually there were at least one million serious accidental poisonings and two million hospitalizations for voluntary ingestion of pesticides (WHO, 1990). An estimated 25 million cases of pesticide exposures and 220,000 deaths occur in developing countries annually (Bertolote et al, 2006). Pesticide-related illnesses in developing countries are not yet considered a public health priority mainly due to the unavailability of reliable data on pesticide use and exposure (Ecobichon, 2001; Konradsen et al, 2003). The home environment is regarded as the most common pesticide-treated indoor environment (WHO, 2002). Indoor pesticide use in homes has the potential to cause adverse effects both to the persons living in the home and to the environment. The effects could be acute such as headaches and nausea (Titlic et al, ,2008) or delayed effects such as intrauterine growth retardation (Levario-Carillo et al., 2004), immune toxicity (Banerjee ,1999), birth defects (Shaw et al ,1999), cancers (Pogoda and Preston-Martin , 1997), nervous system disorders (Rosas and Eskenazi ,2008), skin and eye irritations (Graham et al, 2005) and childhood leukemia (Van Maele-Fabry et al, 2010). Studies assessing household pesticide use in a developing country are not many. In view of the potentially serious effects of ignorant and irresponsible pesticide use, it is important to explore possible aggravating factors in a rural population in a developing country. The objectives of this study were to identify environmental challenges that promote the presence and breeding of pests in households, to identify the types of pests prevalent in households in the area ,to identify methods used in pest control in the area., to audit locally available pesticides and determine their active ingredients, to assess the knowledge of the use, storage and disposal of pesticides by households, to 
access the safety practices associated with household pesticides and to assess impact of pharmacists pest use educational intervention among residents of Kurmin Mashi

\section{MATERIALS AND METHODS}

Study Setting: The study area is Kurmin Mashi, one of the 13 wards in Kaduna South Local Government of Kaduna State. The area is densely populated with a population of 48,247 people, 13,055 households and a mean house size of 3.7 (NPC, 2018). A small river, River Mashi flows sluggishly through the area with garbage being dumped at various points along the banks of the river. Poor garbage disposal, poor drainage and unkempt bushes have contributed to pest infestation in the area.

Study Design/ Data collection: This is a crosssectional study using a structured pre tested questionnaire comprising open and closed-ended questions directed to household representatives. The study population consisted of all the households in the community of Kurmin Mashi ward. The purpose of the study was explained to all the respondents and their consent was obtained in writing, after which the questionnaires were administered to them. Commercially available pesticide samples were collected from retailers and mobile pesticide vendors were also interviewed to see what pesticides they sold. Study participants were then educated on safe use of pesticides and educational leaflets distributed to them. The questionnaires were then re-administered to the participants.

Study Participants: The sample size was 375 households using Krejcie and Morgan table (Krejcie and Morgan, 1970). Simple random sampling technique was used to select participants. The unit of investigation were household heads or any adult household member who was present in the home at the time of study.

Statistical Analysis: Data and information collected were coded entered and analyzed using Statistical Package for Social Science (SPSS) version 17 Statistical Analysis Package (SPSS, 2008). Categorical data was expressed as included frequency and percentages, Pearson's Chi Square test was used to explore association between demographic variables and appropriate outcome measures. A p-value less than 0.05 considered statistically significant.

Outcome Measures: The outcomes were: Proportion of respondents that embraced non-chemical pest control measures, proportion of respondents that embraced hand washing after pesticide application; proportion of respondents that wash their clothes after pesticide application, proportion of respondents that observe appropriate safety measures such as use personal protective equipment during pesticide application and proportion of respondents that regularly read labels before pesticide use.

Study Duration: The study was carried out over a period of 6 months.

\section{RESULTS AND DISCUSSION}

Demographic Characteristics of Respondents: Of the 375 respondents, $146(61 \%)$ were females and 229 $(38.9 \%)$ were males. Majority of respondents were married. $56.8 \%$ of respondents have tertiary education. Only $5.3 \%$ had no form of education, Table 1.

Nearly three quarters, $(73.1 \%)$ of households surveyed had children at home. Almost one quarter (23.2\%) of children was in the under 5 age group. A relatively large proportion $(38.2 \%)$ had poor drainage systems and lacked access to tap water.

Even though $75.2 \%$ used water closet toilet systems, nearly one quarter still used the pit toilet system. Most respondents $(78.1 \%)$ used refuse collectors to dispose of their refuse. However, it was observed that some of these refuse collectors were boys with wheelbarrows who collected the refuse, only to dump it along the banks of the nearby Mashi River, thus further promoting the breeding of pests. Details of risk factors for poisoning are shown in table 2 .

Locally Available Pesticides and their Active Ingredients: Dichlorvos (DDVP) was the most common ingredient contained in household pesticides in the study area. Others were organophosphate insecticides (Chlorpyrifos and Acephate), Carbamates (Propoxur), Rodenticides (Zinc and Aluminum phosphide) and Pyrethroids contained in sprays. Many of the pesticides were unlabeled and their active ingredient could not be ascertained, Table 3

Pests and Pesticide-Use Practices of Respondents: Chickens were the most common domestic pets (16\%), followed by dogs $(12.5 \%)$ and rabbits $(4.3 \%)$. Mosquitoes (39.5\%), cockroaches (24\%) and rats $(15.2 \%)$ were the most troublesome pests in the study population. $99.5 \%$ of households were affected by pests. Nearly half (48.8\%) of households surveyed use chemicals for pest control. More than half, (55.5\%) preferred spray type of insecticides. The family head was mainly responsible for pesticide application. Pesticides were mostly applied to floors and walls. Table 4 details pesticide use practices of respondents. 
Pesticide Safety Practices: More than three quarters (78.7\%) claimed to read instructions on labels before using pesticides. Although an appreciable proportion $(64 \%)$ said they washed their hands regularly after using pesticides, only $4.3 \%$ washed their clothes. Nearly one quarter (23.2\%) applied pesticides in their bedrooms. Even though more than half (55.5\%) stored pesticides safely out of reach of children, some households still stored pesticides in the bedroom and kitchen. Empty pesticides containers were either thrown away or burnt, but about $5 \%$ of respondents recycled used pesticide containers. Details of pesticide use and safety practices are shown in table 5 .

\begin{tabular}{|c|c|c|c|}
\hline \multicolumn{2}{|c|}{ Demographic Characteristic } & \multirow{2}{*}{$\begin{array}{l}\text { Frequency } \\
146\end{array}$} & \multirow{2}{*}{$\begin{array}{l}\text { Percentage } \\
38.9\end{array}$} \\
\hline Sex & Male & & \\
\hline & Female & 229 & 61.1 \\
\hline \multirow[t]{3}{*}{ Age } & $15-29$ & 177 & 47.2 \\
\hline & $30-44$ & 158 & 42.1 \\
\hline & 45 and above & 40 & 10.7 \\
\hline Marital & Single & 175 & 46.7 \\
\hline \multirow[t]{2}{*}{ Status } & Married & 197 & 52.5 \\
\hline & Divorced & 3 & 0.8 \\
\hline Educational & Tertiary & 213 & 56.8 \\
\hline \multirow[t]{3}{*}{ Level } & Secondary & 123 & 32.8 \\
\hline & Primary & 19 & 5.1 \\
\hline & None & 20 & 5.3 \\
\hline
\end{tabular}

Table 2 Risk Factors and Environmental problems $n=375$

\begin{tabular}{|c|c|c|c|}
\hline & Frequency & Percentage \\
\hline \multirow{6}{*}{$\begin{array}{l}\text { Children in the } \\
\text { home } \\
\text { Age range of } \\
\text { children }\end{array}$} & Yes & 274 & 73.1 \\
\hline & No & 101 & 26.9 \\
\hline & $0-5$ & 87 & 23.2 \\
\hline & $6-10$ & 78 & 20.8 \\
\hline & $11-15$ & 77 & 20.5 \\
\hline & $16-20$ & 45 & 12.0 \\
\hline \multirow{6}{*}{$\begin{array}{l}\text { Environmental } \\
\text { problems }\end{array}$} & No gutter & 66 & 17.6 \\
\hline & Blocked gutter & 77 & 20.6 \\
\hline & Unkempt bushes & 44 & 11.7 \\
\hline & Uncollected refuse & 31 & 8.3 \\
\hline & Stagnant Water & 55 & 14.7 \\
\hline & $\begin{array}{l}\text { Absence of tap } \\
\text { water }\end{array}$ & 102 & 27.2 \\
\hline \multirow{6}{*}{$\begin{array}{l}\text { Refuse } \\
\text { disposal } \\
\text { method } \\
\text { Toilet } \\
\text { facilities }\end{array}$} & Throw it outside & 44 & 11.7 \\
\hline & Throw in gutter & 38 & 10.1 \\
\hline & Use refuse collector & 293 & 78.1 \\
\hline & Bush & 5 & 1.3 \\
\hline & Pit latrine & 88 & 23.5 \\
\hline & Water system & 282 & 75.2 \\
\hline \multirow{3}{*}{$\begin{array}{l}\text { Source } \\
\text { water }\end{array}$} & Water sellers & 118 & 31.5 \\
\hline & Well water & 98 & 26.1 \\
\hline & Borehole & 159 & 42.4 \\
\hline \multirow[t]{5}{*}{ Water storage } & In open buckets & 27 & 7.2 \\
\hline & In drums & 190 & 50.7 \\
\hline & In tank & 63 & 16.8 \\
\hline & In Jerry cans & 76 & 20.3 \\
\hline & Do not store water & 19 & 5.3 \\
\hline
\end{tabular}

Self-Reported Adverse Effects of Pesticides: More than one quarter $(36 \%)$ of respondents had experienced some kind of adverse effects from use of pesticides. Adverse effects affected all in the familyfather (14.1\%), children (14.1\%) and mother (12.5\%). Respiratory symptoms were the most common self- reported adverse effect, followed by neurological symptoms. Even though nearly three quarters of adverse effects $(68.3 \%)$ were self- limiting, more than one quarter $(27.7 \%)$ needed to see a doctor to have them resolved. Self- reported adverse drug reactions are shown in table 5:

Table 3 Locally Available Pesticides and Their Active Ingredients. $\mathrm{n}=375$

\begin{tabular}{|c|c|}
\hline Brand name & Active ingredient \\
\hline DD Force & DDVP 1000EC* \\
\hline Shooter & DDVP 1000EC \\
\hline Mash & DDVP $1000 \mathrm{EC}$ \\
\hline Delvap Super & DDVP 1000EC \\
\hline Rush & DDVP 1000EC \\
\hline NOPEST & DDVP 1000EC \\
\hline SNIPER & DDVP $1000 \mathrm{EC}$ \\
\hline Perfect killer & Chlorpyrifos $20 \% \mathrm{EC}$ \\
\hline Magic Insecticide Killer & $\begin{array}{l}\text { Insecticide liquid (no active } \\
\text { Ingredient specified }\end{array}$ \\
\hline Vee Phos tablets & Aluminium Phosphide 57\% \\
\hline Commando rat poison & Zinc phosphide $80 \%$ \\
\hline $\begin{array}{l}\text { Greenleaf cockroach and ant } \\
\text { Killing bait }\end{array}$ & Acephate $2.5 \%$ \\
\hline Pestox powder & Cypermethrin 2\% \\
\hline Rambo Insecticide paper & Transfluthrin $0.45 \%$, \\
\hline Baygon & $\begin{array}{l}\text { Imiprothrin } 0.05 \% \text {, Prallethrin } \\
0.05 \% \text {, Cyfluthrin } 0.05 \%\end{array}$ \\
\hline Rambo PRO & Dichlorvos $\quad 0.5 \%$,Permethrin \\
\hline & $\begin{array}{ll}0.7 \% \quad \text { Propoxur } & 0.5 \% \text {, } \\
\text { Cyfluthrin } 0.02 \% & \end{array}$ \\
\hline Kilit & $\begin{array}{l}\text { Tetramethrin } 0.135 \%, \quad \mathrm{~d}- \\
\text { Allethrin } 0.06 \% \text { Cypermethrin } \\
0.46 \%\end{array}$ \\
\hline Mobil Insecticide & $\begin{array}{ll}\text { Neo-pynamin } & 0.25 \% \text {, } \\
\text { Prallethrin } & 0.04 \% \text {, } \\
\text { Cyphenothrin } 0.05 \% & \end{array}$ \\
\hline
\end{tabular}

Pesticide Safety Practices of Respondents before and after Educational Intervention: There was a statistically significant increase in proportion of households that used non chemical methods after educational intervention (Chi Square $=11.211, \mathrm{df}=5$, $\mathrm{P}=0.0473$ ). Also the proportion of households that took precaution during and after pesticide application was significantly increased (Chi Square $=42.694$, $\mathrm{DF}=4 . \mathrm{P}<0.001$ and Chi Square $=48.700, \mathrm{df}=5, \mathrm{P}$ $<0.001)$. The proportion of those who read labels before pesticide use was not significantly affected after intervention. $(\mathrm{P}=0.3841)$, Table 6 . This study shows that pesticides are widely used in many homes in Nigeria. Almost one quarter of children in these homes were in the under 5 age group. Children are an extremely vulnerable, high-risk group for pesticide exposure (Fenske et al, 2002). The 1996 U S Food Quality Protection Act, legislation requires the Environmental Protection Agency to place particular emphasis on assessing potential risk from pesticides to infants and children (Suhre, 2000). In US in 2008, pesticides were the ninth most common substance 
reported to poison control centers, and approximately $45 \%$ of all reports of pesticide poisoning were for children (Roberts and Karr, 2012). Given the high level of exposure, there may be need for concerted efforts to protect Nigerian children from the harmful effects of household pesticides. About one quarter of respondents applied pesticides every day, while about half of them applied pesticides on a weekly basis. The mistaken belief that daily pesticide use offers more protection than less frequent application needs to be corrected. More is not the better (UIE, 2018). Frequent application of pesticides, if not done correctly in the right quantities can pose health risk to household members. Knowledge of pesticide attributes as contained in the label is critical to safety and influences the manner in which a pesticide product is used (Leonard and Wogalter, 2000). Problems associated with the use of pesticides in and around the home usually occur as a result of individuals failing to educate themselves on proper safety practices associated with pesticide use (Oyler et al, 2000). When pesticide labels are properly read and instructions adhered to, problems associated with pesticide use are minimized. The public should be helped to appreciate the need to read pesticide labels each and every time. Pesticide manufacturers should also ensure that labels are legible, understandable and in language comprehensible by majority of users (Waichman et al, 2007). Only about one quarter of respondents indicated that they washed both their hands and their clothes after pesticide use. Washing of hands only does not offer adequate protection. Clothing worn during their application should also be washed (USEPA, 2012).

Table 4 Pesticide Safety Practices $n=375$

\begin{tabular}{|c|c|c|c|}
\hline \multicolumn{2}{|c|}{ Pesticide safety practice } & \multirow{2}{*}{$\begin{array}{l}\text { Frequency } \\
295\end{array}$} & \multirow{2}{*}{$\begin{array}{l}\text { Percentage } \\
78.7\end{array}$} \\
\hline Read & Yes & & \\
\hline instructions & No & 80 & 21.3 \\
\hline \multirow{5}{*}{$\begin{array}{l}\text { Precaution } \\
\text { taken }\end{array}$} & Always in the room after application & 25 & 6.7 \\
\hline & Always leave the room after application & 246 & 65.6 \\
\hline & Use face mask during application & 17 & 4.5 \\
\hline & Use hand gloves during application & 24 & 6.4 \\
\hline & Wash hands after use & 63 & 16.8 \\
\hline \multirow{11}{*}{$\begin{array}{l}\text { Other } \\
\text { precautions } \\
\text { taken after } \\
\text { application } \\
\text { Indoor } \\
\text { pesticide use }\end{array}$} & Wash hands only & 240 & 64 \\
\hline & Wash clothe & 16 & 4.3 \\
\hline & Wash hands and clothes & 106 & 28.3 \\
\hline & None & 13 & 3.5 \\
\hline & Kitchen & 27 & 7.2 \\
\hline & Bedroom & 87 & 23.2 \\
\hline & Store & 10 & 2.7 \\
\hline & Toilet & 11 & 2.9 \\
\hline & All rooms & 222 & 59.2 \\
\hline & Outside & 7 & 1.9 \\
\hline & Sitting room & 11 & 3.0 \\
\hline \multirow{7}{*}{$\begin{array}{l}\text { Pesticide } \\
\text { storage }\end{array}$} & Store & 61 & 16.3 \\
\hline & Garage & 25 & 6.7 \\
\hline & Kitchen & 9 & 2.4 \\
\hline & Bedroom & 30 & 8.0 \\
\hline & Bathroom & 35 & 9.3 \\
\hline & High shelf out of reach of children & 208 & 55.5 \\
\hline & others & 7 & 1.8 \\
\hline \multirow{5}{*}{$\begin{array}{l}\text { Length of } \\
\text { storage }\end{array}$} & Less than 6 months & 295 & 78.7 \\
\hline & 6-12 months & 63 & 16.8 \\
\hline & $12-24$ months & 10 & 2.7 \\
\hline & More than 24 months & 6 & 1.6 \\
\hline & Anytime it is finished & 1 & 1.3 \\
\hline \multirow{4}{*}{$\begin{array}{l}\text { Disposal of } \\
\text { container }\end{array}$} & Rinse and use for something else & 18 & 4.8 \\
\hline & Throw away & 284 & 75.7 \\
\hline & Burn & 72 & 19.2 \\
\hline & Give children to play with & 1 & 0.3 \\
\hline
\end{tabular}

More than half of the respondents in the study claimed to store pesticides on high shelves out of reach of children. Failure to store pesticides properly can result in fatal or near fatal accidental ingestion by children resulting from severe acute pesticide poisoning (Lemus and Abdelghani, 2000). Most respondents in the study threw away pesticide containers after use. Proper disposal of pesticide containers is important to prevent environmental contamination and access to the containers by curious children and pets (Brown, 2018). Self-reported adverse effects in the study included respiratory symptoms such as sneezing, vomiting, headache, and dizziness. Even though most were self-limiting, about one quarter of respondents sought medical attention. 
Table 5 Self-Reported Adverse Effects of Pesticides. n=375

\begin{tabular}{lll}
\hline Health problem & Frequency & Percentage \\
\hline Yes & 135 & 36 \\
No & 206 & 54.9 \\
Don't know & 34 & 9.1 \\
Person affected & & \\
Father & 53 & 14.1 \\
Mother & 47 & 12.5 \\
Child & 53 & 14.1 \\
Type of health problem & & \\
Sneezing & 90 & 24 \\
Vomiting & 14 & 3.7 \\
Headache & 24 & 6.4 \\
Dizziness & 19 & 5.1 \\
Accidental ingestion & 5 & 1.3 \\
Action taken & & \\
Throw away pesticide & 11 & 2.9 \\
See a doctor & 104 & 27.7 \\
Did not do anything & 236 & 68.3 \\
Others & 4 & 1.1 \\
\hline Others include local treatment, saw a chemist and stopped using it
\end{tabular}

Table 6 Pesticide Safety Practices of Respondents before and after Educational intervention. n=375

\begin{tabular}{|c|c|c|c|c|c|c|}
\hline Item & & $\begin{array}{l}\text { Pre- } \\
\text { Intervention } \\
\mathrm{N}=375 \\
\mathrm{~N}(\%)\end{array}$ & $\begin{array}{l}\text { Post- } \\
\text { Intervention } \\
\mathrm{N}=375 \\
\mathrm{~N}(\%)\end{array}$ & $\begin{array}{l}\text { Chi } \\
\text { Square }\end{array}$ & Df & P Value \\
\hline Rat glue & & $15(4.0)$ & $26(6.9)$ & & & \\
\hline Rat trap & & $16(4.3)$ & $29(7.7)$ & 11.211 & 5 & 0.0473 \\
\hline Use of cats & Non-Chemical methods & $12(3.2)$ & $21(5.6)$ & & & \\
\hline $\begin{array}{l}\text { Mosquito nets on } \\
\text { doors and windows }\end{array}$ & & $92(24.5)$ & $89(23.7)$ & & & \\
\hline $\begin{array}{ll}\text { Long } & \text { lasting } \\
\text { insecticide } & \text { treated } \\
\text { nets } & \end{array}$ & & $57(15.2)$ & $50(13.3)$ & & & \\
\hline Use of chemicals & & $183(48.8)$ & $160(42.7)$ & & & \\
\hline Read instructions & Yes & $295(78.7)$ & $284(75.7)$ & & & 0.3841 \\
\hline \multirow{6}{*}{ Precaution taken } & & $80(21.3)$ & $91(24.3)$ & & & \\
\hline & $\begin{array}{l}\text { Always in the room after } \\
\text { application }\end{array}$ & $25(6.7)$ & $27(7.2)$ & & & \\
\hline & $\begin{array}{l}\text { Always leave the room after } \\
\text { application }\end{array}$ & $246(65.6)$ & $310(82.7)$ & & & \\
\hline & Use face mask during application & $17(4.5)$ & $51(13.6)$ & \multirow[t]{3}{*}{42.694} & \multirow[t]{3}{*}{4} & \multirow{3}{*}{$<0.0001$} \\
\hline & $\begin{array}{l}\text { Use hand gloves during } \\
\text { application }\end{array}$ & $24(6.4)$ & 41(10.9) & & & \\
\hline & Wash hands after use & $63(16.8)$ & $216(57.6)$ & & & \\
\hline
\end{tabular}

Further studies will be required to ascertain chronic adverse effects in the study population. The most common ingredient in locally available pesticides was (Dichlorvos DDVP). Dichlorvos, acephate and chorpyrifos are organophosphates that have been restricted by US EPA due to potential hazardous effects on human health and the environment (Brown, 2018). Exposure could result from spills, improper use, poor storage or inadvertent poisoning (Lemus and Abdelghani, 2000). Other ingredients contained in locally available pesticide can be equally hazardous. Zinc phosphide (Commando rat poison) has been reported in poisonings while Aluminum phosphide (Vee phos tablet) is a highly toxic agent that inhibits mitochondrial cytochrome $\mathrm{C}$ oxidase and leads to pulmonary and cardiac toxicity with mortality ranging from $37 \%$ to $100 \%$ (Kamal et al,1999; Goel and Aggarwal , 2007). More than half of respondents preferred spray type pesticide containing pyrethroids. Synthetic pyrethroid insecticides have become increasingly popular pesticides following outright bans or limitations on the use of Organophosphates and carbamates (Maund et al, 2001; Luo and Zhang, 2011, Feo and Barcelo, 2010). The preference for pyrethroids may be due to the fact that they have better activity profile including high efficiency, wide spectrum, low mammalian and avian toxicity and they are more biodegradable (Pap et al, 1999, Walker ,2000, Amweg et al , 2005). 


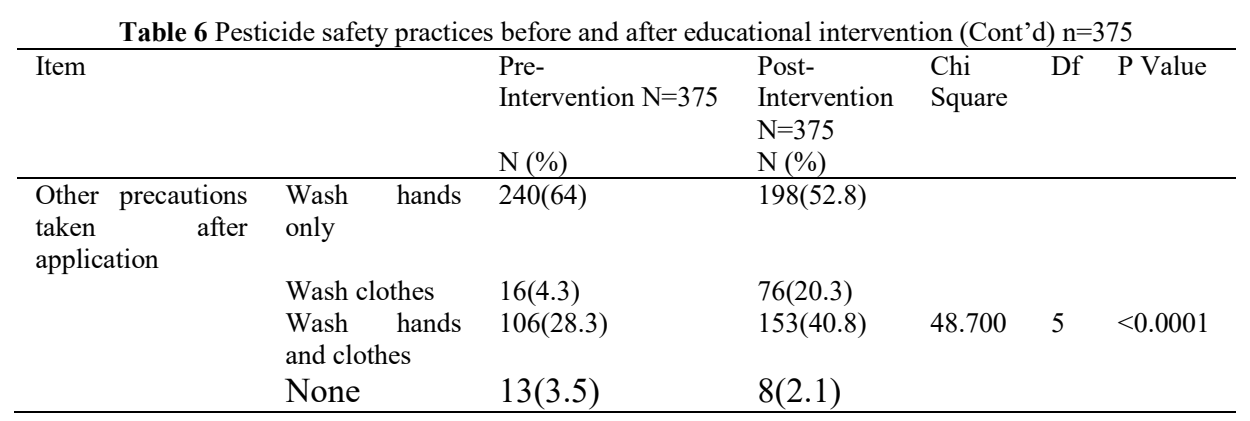

Some of the pesticides in containers were unlabeled and their active ingredient could not be ascertained. This is quite hazardous since safety measures associated with use of unlabeled products cannot be ascertained. Limitations of the study include recall bias among respondents as to precisely how they used pesticides. There may also be some information bias as some respondents may not want to reveal the pests in their homes, for example bedbug which is usually associated with poor hygiene. Another limitation of the study is the limited time available for educational intervention. Increasing the length and frequency of educational intervention may have been able to produce more statistically significant pesticide use behavior change in the study population.

Conclusion: Many locally available pesticides were un-labeled. The major constituent of labelled pesticides was Dichlorvos (DDVP). Unsafe pesticide handling practices were common. The most common self -reported adverse effect was respiratory symptoms. Educational intervention improved pesticide safety practices such as hand washing, washing of clothes, reduction in use of chemical pesticide and perusing pesticide labels before use. Educational intervention by health professionals could be a viable option in designing strategies to reduce threat to individual and public health resulting from ignorant and irresponsible use of household pesticides.

Acknowledgements: We are grateful to the village head and residents of Kurmin Mashi for their cooperation and support.

\section{REFERENCES}

Amweg EL; Weston, DP; Ureda NM (2005) Use and toxicity of pyrethroid pesticides in the Central Valley, California, USA. Environ. Toxicol. Chem. 24, 966-972.

Banerjee BD (1999) The influence of various factors on immune toxicity assessment of pesticide chemicals, Toxicol. Lett. 107(1-3):21-31.
Bertolote JM, Fleischmann A, Eddleston M; Gunnell D, (2006) "Deaths from pesticide poisoning: a global response," B.J. Psychiatry, (189): 201-203

Brown AE. Restricted use of pesticides [Internet site] University of Maryland, Maryland Cooperative Extension. Available from: http://www.pesticide.umd.edu/leaflets/pil2.pdf Accessed 15/07/2018

Ecobichon DJ (2001) "Pesticide use in developing countries," Toxicology 160, (1-3): 27-33

Fenske RA; Kedan G; Lu C; Fisker-Andersen JA; Curl CL.(2002) Assessment of organophosphorus pesticide exposure in the diets of preschool children in Washington State. J Expo. Anal. Environ. Epidemiol, 12:21-28

Feo M; Eljarrat E; Barcelo' D (2010) Determination of pyrethroid insecticides in environmental samples. Trends Anal. Chem., 29(7):692-705.

Goel A; Aggarwal P. (2007) Pesticide Poisoning. The Natl. Med. J. India, 20: 182-91.

Graham JP; Corella BV; Avitia DR; Gurian P. (2005) The in-home environment and household health: a crosssectional study of informal urban settlements in northern Mexico, Int. J. Environ. Res. Public Health, 2, (3-4):394-402.

Gubler DJ (1998) "Resurgent vector-borne diseases as a global health problem," Emerg. Infect. Dis., 4, (3): $442-450$

Guinovart C; Navia MM; Tanner M; Alonso PL, (2006) "Malaria: burden of disease," Curr. Mol. Med., 6, 2:137-140

Kamal AA; Abdel-Hamid DM; Hatch DL; Ahmed AN.(1999) "Epidemiological study of the claimed zinc phosphide intoxication in Kom Ombo district April 1996," J. Egypt Public Health Assoc., 74(12):175-191 
Konradsen F; Van Der Hoek W; Cole DC; Hutchinson G; Daisley H; Singh S et al.(2003) "Reducing acute poisoning in developing countries-options for restricting the availability of pesticides," Toxicology, 192, (2-3):249-261

Krejcie R V; Morgan D W (1970) Determination of sample size for research activities. Educ. psychol. Meas. 1970; 30:607-610

Lemus R; Abdelghani A (2000) Chorpyrifos- an unwelcome pesticide in our homes. Rev. Environ. Health, 15:421-433.

Leonard S; Wogalter MS (2000). What you don't know can hurt you: household products and events. Accid. Anal Prev, 32 (3):383-388

Levario-Carillo M; Amato D; Ostrosky-Wegman P; Gonzalez-Horta C; Corona Y and Sanin LH. (2004) Relation between pesticides exposure and intrauterine growth retardation, Chemosphere, 55(10): 1421-1427.

Luo Y; Zhang M (2011). Environmental modelling and exposure assessment of sediment-associated pyrethroids in an agricultural watershed. PLOS ONE 6(1): e15794. Doi: 10.1371/journal.pone.0015794.

Maund SJ; Travis KZ; Hendley P; Giddings JM; Solomon KR (2001). Probabilistic risk assessment of cotton pyrethroids: Combining landscape-level exposures and Eco toxicological effects data to characterize risks. Environ. Toxicol. Chem. 20: 687-692.

National Population Commission, Nigeria Available at https://www.informationng.com/2018/04/see-thecurrent-population-of-nigeria-according-to-nationalpopulation commission.html.Accessed 15/9/18

Oyler TO; Gripp SI; Richards KM; Hock WK. (2000) Safe Use of Pesticides around the Home. Agrochemical Fact Sheet. . Pp 1-10

Pagoda J; Preston-Martin S. (1997) Household pesticides and risk of paediatric brain tumours. Environ. Health Perspect, 105, (11):1214-1220.

Pap L; Bajomi D; Szekely, I (1996) The pyrethroids, an overview. International Pest Council, 38(1):15-19.

Roberts JR; Karr CJ (2012) Council on Environmental Health- Pesticide Exposure in Children. Paediatrics, 130: e1765-e1788.

Rosas LG; Eskenazi B (2008). Pesticides and child neurodevelopment, Curr. Opin. Paediatr, 20, (2):197-197.
Shaw GM; Wasserman CR; O’Malley CD; Nelson V; Jackson RJ (1999). Maternal pesticide exposure from multiple sources and selected congenital anomalies. Epidemiology, 10, (1): 60-66.

Statistical Package for Social Science (SPSS) (2008). Version 17 SPSS for Windows, Chicago: SPSS Inc.

Suhre FB (2000). Variability in pesticide residues. The US experience. Food Addict. Contam. 17:497-501

Titlic M; Josipovic-Jelic Z; Punda A (2008) Headache caused by pesticide-a review of the literature, Acta Med. Croatia, 62, (2): 233-236.

United States Environmental Protection Agency (2012). Pesticide Safety Tips, Pesticides: Topical and Chemical Fact Sheets. Available at https//www.epa.gov. Accessed 25/4/18

University of Illinois Extension. Apply Pesticides Accurately and Safely, 57 Ways to Protect your Home Environment (and Yourself). Available at www.thisland.illinois.edu/57ways/57ways $48 \mathrm{html}$ Accessed on 20/09/2018

Van Maele-Fabry G; Lantin AC; Hoet P; Lison D (2010) Residential exposure to pesticides and childhood leukemia: a systematic review and meta-analysis, Environ. Int., 37 (1): 280-291.

Waichman AV; Evaldice E; Celso da Silva Nina N. (2007) Do farmers understand the information displayed on pesticide labels? A key question to reduce pesticide exposure and risk of poisoning in the Brazilian Amazon, Crop Protection, 26(4):576583

Walker K. (2000) Cost-comparison of DDT and alternative insecticides for malaria control. Med.Vet. Entomol, 14:354-354.

Wilcox BA; Echaubard P; de Garine-Wichatitsky M; Ramirez B (2019) Vector-borne disease and climate change adaptation in African dry land socialecological systems. Infect. Dis. Poverty 8 (1):36 doi: 10.1186/s40249-019-0539-3

World Health Organization (1990) Public Health Impact of Pesticides Used in Agriculture, WHO, Geneva, Switzerland, 1990.

World Health Organization (2002) Assessment of exposure to indoor contamination. Rev Environ Contam Toxicol., 175:1-46 